\title{
The Nature of the Fertile Spike in the Ophioglossaceae.
}

\author{
BY \\ MINTIN A. CHRYSLER, \\ Associate Professor of Botany, Univ. of Maine.
}

With Plates I and II, and sixteen Figures in the Text.

SPECULATION on the morphological nature of that unusual organ of $\checkmark$ the Ophioglossaceae known as the fertile segment or fertile spike dates at least from the time of Roeper, who in 1826 (20) suggested that in Botrychium Lunaria the leaves arise in pairs, one sterile and one fertile, with their petioles fused. In 1843 Roeper extended his views to the whole family (21). But Presl (19) pointed out that the base of the petiole ('stipe') contains only a single bundle, and hence he considered the fertile spike to be a pinna of the leaf. Apparently influenced by this criticism and that of Mettenius (17), Roeper in 1859 (22) replaced his earlier suggestion by the view that the fertile spike represents two fused pinnae, namely the basal ones of a leaf, the rest of the pinnae of which are sterile. He also adduced teratological evidence in support of his view, and noted that the vascular supply of the fertile spike is double in species of Botrychium. It was shown by Holle (14) that Roeper's theory might be applied to Ophioglossum, since the origin of the vascular supply of the fertile spike is similar to that in Botrychium.

The suggestion of Braun (7) that the fertile spike of Ophioglossum is the first leaf of a bud in the axil of the ordinary sterile leaf, with which its stalk is confluent, has not received wide acceptance.

Goebel $(12,13)$ has adduced the view that the fertile spike of Botrychium is the lowest fertile pinna of a leaf, but that it arises in a ventral instead of a lateral position.

All of the theories so far outlined assume that the aerial organ of the Ophioglossaceae consists of one or more leaves which have been derived $\mathcal{V}$ from the leaf of some fern-like plant by a process of specialization; in other 드 words, that the ancestry of the Ophioglossaceae is to be looked for among the ferns. Since Botrychium is the most fern-like genus of the family, it is regarded as the primitive genus. 
Of quite different opinion is Bower, who since I89 I (3) has offered evidence for considering the fertile spike of Ophioglossum to be a septate sporangium arising on the ventral face of a sporophyll. Thus the aerial organ of Ophioglossum represents one of the sporophylls of the cone of Lycopodium. From Ophioglossum are derived the different species of Botrychium, which are arranged in an ascending series, and Helminthostachys takes its place as an elaborated pattern from the same origin. According to this view the ancestors of the Ophioglossaceae are microphyllous forms such as the Lycopods. Other writers, especially Celakovsky (10), have suggested a common origin for Ophioglossaceae and Lycopod-
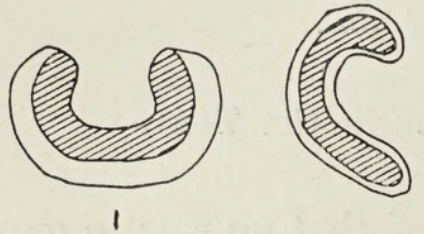

2.
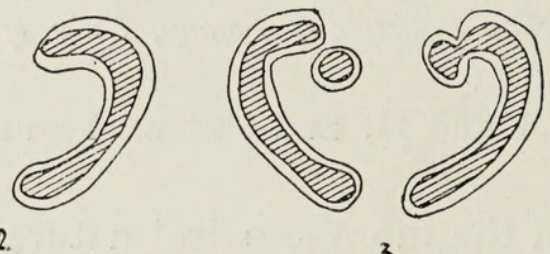

3
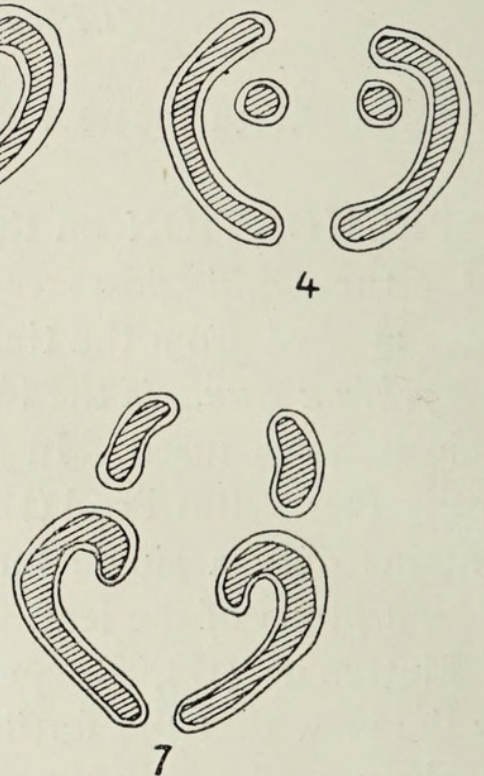

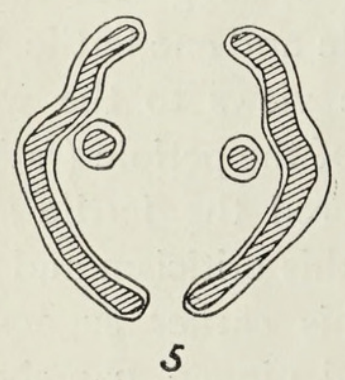

5

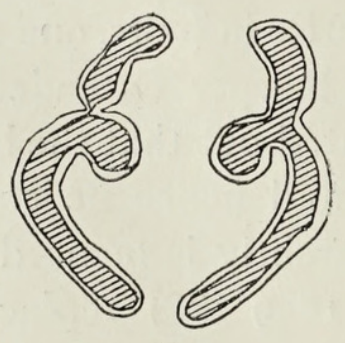

6

FIGS. I-7. Diagrams illustrating the origin of the strands which supply the fertile spike in Botrychium virginianum. Fig. I is from the lowest section. Xylem is shaded, phloem left clear. The adaxial side of the petiole is placed upward.

iales, but none have supported the theory by any such array of evidence as Bower presents.

Campbell $(8,9)$ would give Ophioglossum a place much nearer the base of the genealogical tree, deriving the fertile spike directly from a sporogonium such as that of Anthoceros. An extended account of the different theories will be found in Bower's monograph on the Ophioglossaceae (4).

When the affinities of a group are subject to such wide variations of opinion, evidence should be sought in all quarters, and the attempt is here made to bring forward anatomical data which bear in no uncertain way upon the question. The work here described has to do chiefly with the origin of the vascular strands which supply the fertile spike. Although this has been examined in several European forms, the modern method of using serial sections does not seem to have been employed; further, Botrychium virginianum, which affords the key to the situation, has strangely enough been overlooked from this point of view. 
The vascular supply of the aerial part of Botrychium virginianum arises as a single curved collateral strand (Text-fig. I) from one side of the hollow cylinder of the underground stem, leaving a distinct gap. At a height of a centimetre or so the strand divides into two, and assumes a somewhat horseshoe shape, with its adaxial side concave. At about this level it gains an internal phloem and thus becomes concentric (Fig. 2); it retains this character as it rises through the stipe. At a distance of I-2 $\mathrm{cm}$. below the point where the fertile and sterile segments separate, each arm of the horseshoe-shaped strand becomes hooked, and soon the tip of each hook breaks off as a small circular concentric strand (Fig. 3),

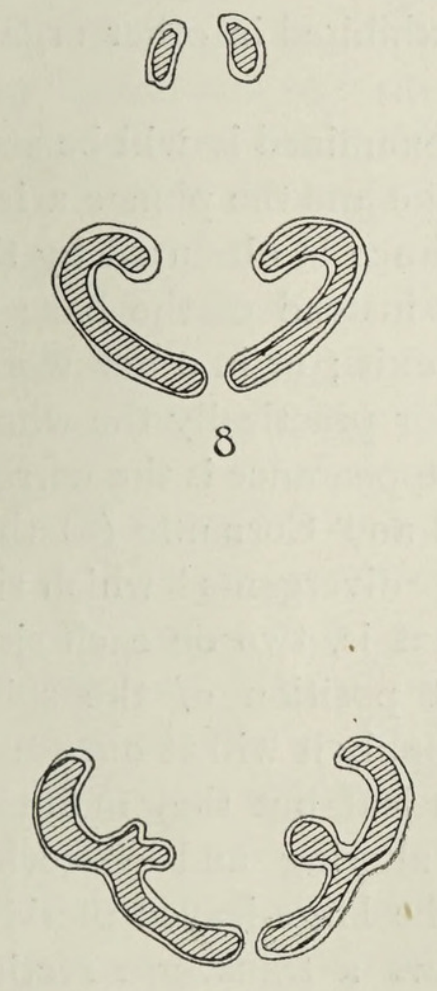

II

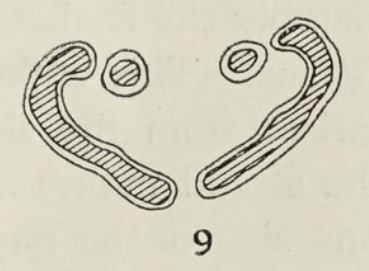

9
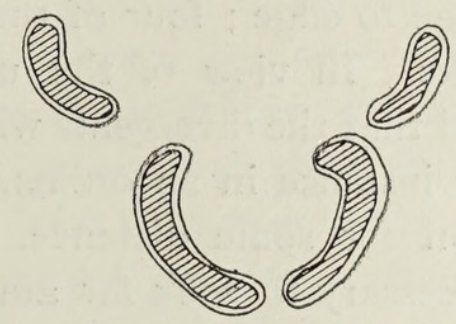

12

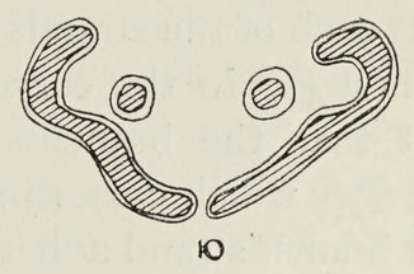

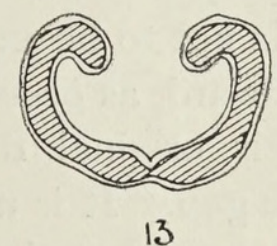

13

FIGS. 8-I3. Diagrams illustrating the origin of the strands which supply the first pair of pinnae of the sterile segment in Botrychium virginianum. Fig. 8 follows Fig. 7 in the sequence.

which a little higher up joins the inner face of the large strand (Fig. 5). Just at this level the adaxial portion of each arm of the main strand breaks off (Figs. 6, 7), and the two bundles so formed approximate to a certain extent and constitute the vascular supply of the fertile spike. Thus the fertile spike has a pair of bundles, as was pointed out long ago by Roeper. Before inquiring into the meaning of the peculiar course of the strands just traced, it will be well to follow up the main vascular supply into the sterile segment. The two main strands may unite at about this level or may remain slightly separated, and in any case they again begin precisely the same series of changes as has been described above, namely, the double strand assumes the form of a horseshoe with each point incurved 
(Fig. 8), these points break off (Figs. 9, I0) and the two small bundles so formed join the main strands on their inner face at a slightly higher level (Fig. II), then the adaxial portions of the main strands break off (Fig. 12) and supply leaflets or pinnae on each side. Here of course the branching strands do not approximate, but diverge as they pass out to pinnae. The same process is gone through in connexion with the exit of the traces of the next pair of pinnae. The identity of the mode of origin of the vascular supply of the fertile spike and that of a pair of pinnae of the leaf indicates, unless there is evidence to the contrary, that the fertile spike represents two fused basal pinnae of a leaf, thus supporting the theory proposed by Roeper (22). But it is necessary to show that the mode of origin so described corresponds to the mode exhibited in other organs admitted to be leaves.

If the figures just referred to are attentively examined it will be seen that each of the strands which supply the fertile spike and the pinnae arises from a gap in the curved leaf-trace. This appearance is obscured by the fact that the branch strand arises from the side instead of the base of the gap, which closes just as the strand makes its exit ; or in other words the branch strand adheres to one side of the gap for practically the whole length of the gap. That this interpretation of the appearance is the correct one is borne out by the observation of Bertrand and Cornaille (2) that in the basal part of the petiole there are fourteen 'divergents' which run more or less united edge to edge; four of these, that is, two on each side, supply the fertile spike. In view of the upright position of the spike it is not to be expected that the divergents which supply it will at once turn outward, as occurs for instance in an ordinary fern leaf, but they maintain their original direction for some distance, thus altering and obscuring the gap. It is not necessary to seek far among the large-leaved pteridophytes for petiolar traces with gaps. Fig. I7 shows a transverse section through the midrib of Todea barbara at the level where two leaflets arise. It will be seen that the vascular supply of a leaflet leaves a wide gap at its exit from the curved leaf-trace. In the related genus Osmunda the same may be seen, but in this genus the gap is sometimes so narrow that a section taken just above the point of origin of the traces of pinnae shows no gap. This is represented in Fig. I 8, near which (Fig. 19) has been placed a photograph of the corresponding region in Botrychium virginianum; the similarity is too marked to be overlooked. Sinnott (23) has recently shown that this feature is of general occurrence in the Osmundaceae. In Polypodiaceae the leaf-trace has the same general shape, and the gaps left by the departure of the vascular strands of the pinnae are generally so narrow that no fundamental tissue is to be seen in them, but it can easily be made out that these strands do not break off from the free edges of the petiolar trace, but are pinched off from the projecting corners of the trace. Only in com- 
paratively small-leaved genera or species (e.g. Pteris cretica) does evidence of the gap disappear, and the lateral bundles spring from the edge of the petiolar trace. Bertrand and Cornaille (l. c.) have argued that the condition found in Osmundaceae is to be regarded as primitive, and the conditions seen in Polypodiaceae seem to be derived by reduction. It may be added that the structure of the midrib of the pinnae in Marattia is of the same general structure as the petiole of Todea, namely, the vascular supply of the pinnules arises by distinct gaps. The split or divided $U$ seen in the petiolar strand of Botrychium virginianum recurs in numerous Polypodiaceae, e. g. the stipe of Onoclea, Pteris, spp., Asplenium, spp., so this feature forms no drawback to the derivation of Botrychium from fern ancestors. In Onoclea the leaf-trace is double near the base of the ieaf, but higher up the two halves join to form a U-shaped strand; the same sometimes happens in $B$. virginianum. In both these cases the leaf-trace arises as a single strand, while the supply of the fertile spike of Botrychium is double from its origin upward. The diagrams shown in Fig. I-I3 were made from a fairly small specimen; in well-grown specimens the plan is less apparent on account of the parting asunder of some of the 'divergents' which compose the leaf-trace, though the plan is in reality precisely the same as in smaller plants.

Of the species examined, $B$. virginianum seems to be the most fernlike. This appears not only in the mode of origin of the vascular supply of the pinnae, but in the amphiphloic feature of the leaf-trace and the distinctness of the divergents. Several varieties of $B$. ternatum have also been available for study, namely, intermedium, dissectum, and obliquum, which has lately been recognized as a distinct species. ${ }^{1}$ These varieties merge into one another in a way that makes distinctions difficult. The anatomy of these varieties offers no basis for distinguishing them, and they may here be considered together.

The leaf-trace of $B$. ternatum, like that of all other species, leaves a wide gap where it parts from the central cylinder. At first it is only slightly curved (Fig. I4), but it rapidly assumes the form of the letter C, and may almost form an $O$. From the free edges arise the two strands (Fig. I5) which supply the fertile spike. These strands may fuse more or less just above their point of origin (Fig. I6), but separate higher up. All of the strands so far mentioned are collateral, in distinction to those of $B$. virginianum which are concentric. The branches of the fertile spike show interesting transitions from the condition seen in the sterile part to that described for B. virginianum. In some specimens these branches manifestly arise from gaps, as is illustrated in Fig. 20. A small strand (hereafter called the marginal strand) arises from each edge of the main

x Lyon (Botan. Gaz., xl. 455-8, 1905) even proposes to separate it into a new genus, Sceptridium, on the basis of gametophyte characters. 
vascular strand, and higher up joins again as shown in the figure; but a new feature appears, in that half of the marginal strand remains with the main strand, while the other half passes out with the branch, which is accordingly $\mathrm{C}$-shaped. The branch becomes concentric by acquiring an internal phloem as it passes out. In other specimens only the upper part of the marginal strand is present, that is, the part shown at the right-hand side of Fig. 20 ; following the series downward the marginal strand parts from the main strand (Fig. 20, right-hand side), swerves towards the edge of the latter but does not reach it, for it dwindles away and disappears. In other cases the marginal strand passes down only a short distance before it disappears, or its upper end may even be represented merely by a slight projection from the main strand. In such cases the branches which supply a group of sporangia appear to arise from the edge of the main strand. Since only the upper part of the marginal strand is present in these transitional cases, the strand can have no function; its xylem cannot conduct water when it has
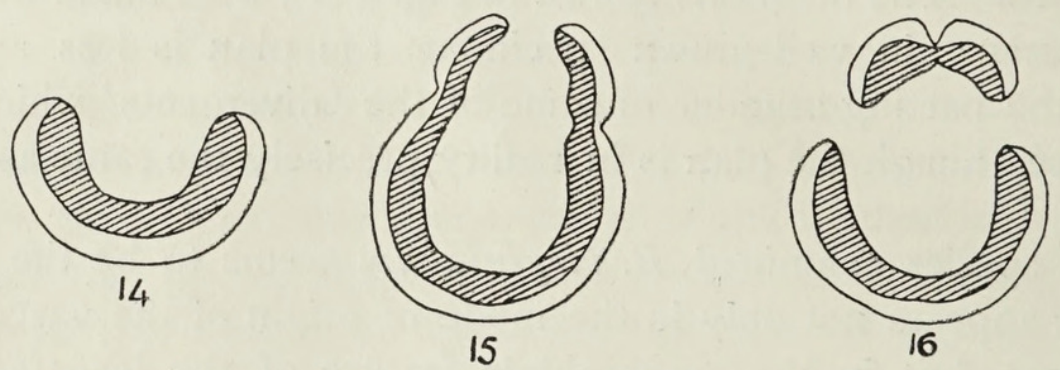

FIGS. I4-16. Diagrams illustrating the origin of the strands which supply the fertile spike in Botrychium ternatum.

no attachment below; hence it must be regarded as a vestigial structure, derived from the condition seen in all regions of the leaf of $B$. virginianum and in the fertile spike of some specimens of B. ternatum. This evidence plainly goes to support the view that $B$. virginianum has been derived from some less specialized fern, and that $B$. ternatum has been derived from some such plant as $B$. virginianum by a process of reduction in respect to the vascular system. The location of the internal phloem also supports this view. In most ferns this is present in both stem and leaf; in B. virginianum it is absent from the stem but occurs in the leaf through most of its length; in B. ternatum it is to be seen only in the remote branches of the leaf, especially in its fertile part; in other species its presence has not been recorded. It is becoming pretty well recognized that the leaf is one of the places where primitive features are apt to persist, and in the genus Botrychium we have a case where a structure is seen to gradually disappear from this organ.

The two species B. ramosum (Roth), Aschers (B. matricariaefolium, A. Br.), and B. lanceolatum (S. G. Gmel.), Angs., are usually associated in schemes of classification, and the anatomical features bear this out. 
Material of these species was secured from Maine and Massachusetts. These species show their relation to $B$. ternatum by the similar form of the petiolar strand, the two parts of which almost meet adaxially, so that the form is nearly that of the letter O. From the adaxial edges break off the two strands which supply the fertile spike; these may approximate, but do not fuse. In both fertile and sterile segments the branches of the vascular system arise in the manner just stated. Thus the gap left by the exit of branch traces in $B$. virginianum has disappeared in the species under consideration.

Botrychium Lunaria was examined by Roeper and others, who found the double vascular supply of the fertile spike. By soaking out and imbedding herbarium material, I have been able to verify the earlier accounts. The whole vascular system of the leaf is markedly two-sided; the leaf-trace splits before the leaf has become free from the stem, and the two halves diverge rather widely. The strands which supply the fertile spike and also those which supply the lobes of the leaves arise from the free adaxial edges of the main strands. A slight prominence on the inner side of the latter at the point of departure of a branch may represent a vestige of the 'lateral strand' described under $B$. ternatum. If such is the case $B$. lunaria is to be regarded as a reduced species derived from more fernlike ancestors.

Botrychium simplex, material of which I owe to Mr. J. C. Parlin, looks externally like a reduced Lunaria, and its internal structure bears this out. Its vascular system is quite similar, but the strands are smaller, especially those of the sterile segment, so that those of the sterile and fertile parts are of about equal size. The two petiolar strands divide into adaxial and abaxial parts, so that the gap seen in B. virginianum has quite disappeared. The two strands of the fertile spike remain separate throughout their length.

Certain abnormal forms of B. obliquum, Muhl., may next be considered. Through the great kindness of Mr. F. W. Bachelder a supply of this interesting material, collected in the vicinity of Manchester, New Hampshire, has been available for study. The external features of the specimens have been briefly described by Mr. Bachelder (1), and the peculiarity consists in the presence of two or three fertile spikes in place of one, or in the presence of one or more fertile pinnae among the ordinary sterile ones. Certain of these specimens were photographed, then soaked up and swelled out by means of warm dilute ammonia, and afterwards imbedded and cut into serial sections in the usual manner.

In the simplest of these cases, two similar fertile spikes arise in the normal position (Fig. 24), diverging slightly right and left. Externally they appear to form a pair, and the structure corresponds to this view, for the petiolar strand has in transverse section the form of a $U$, from each 
extremity of which arises a strand which supplies one of the two fertile spikes. Here we appear to have an actual realization of the theory of Roeper, and the facts are readily explained on the assumption that these two fertile spikes represent the two basal (fertile) pinnae of the leaf. Botrychium has often been compared with Aneimia; the resemblance of the present form to the tropical fern is so striking that there has been introduced for comparison a photograph of a specimen of Aneimia tomentosa kindly furnished by the Curator of the Gray Herbarium. The resemblance extends to the internal structure, for Aneimia has a trough-shaped leaf-trace from the edges of which are given off the strands that supply the fertile pinnae. Specimens of B. obliquum showing two fertile spikes have been collected also at Sandwich, N.H., Conway, N.H., Topsham, Me., Utica, N.Y., Friendsville, Pa. Mrs. Britton, speaking before the Torrey Botanical Club, refers to the 'frequency of the fronds forking' in specimens of $B$. ternatum (vars.) found in the Berkshire Hills, Mass. ${ }^{1}$ These facts scarcely tally with Bower's statement $(4$, p. 42$)$ that in the large-leaved forms abnormalities ' are, if existent at all, so rare that they are seldom or never represented in herbaria, or recorded in the books'. In some of the specimens (Fig. 28) the two spikes are fused for a short distance from the base, or for half-way up the stalk. A series of sections through one of these showed the usual double vascular supply with partial fusion of the two bundles in the lower part of the stalk.

Other specimens show three fertile spikes (Fig. 26), one in the normal position and two smaller ones forming a pair springing from a point I $2-I 5 \mathrm{~mm}$. higher on the petiole. The leaf-trace is as usual $\mathrm{U}$-shaped in transverse section; from its adaxial edges arise two strands which soon meet to produce a shallow $U$ and run up into the lowest fertile spike. After running onward for about a centimetre the leaf-trace gives off a strand on each side from a point near but not at the edge; the appearance is much like the figure (18) of Osmunda, indicating that the gap is too narrow to allow the fundamental tissue to be continuous through it. Each of these strands is concentric, and supplies one of the paired spikes. Certain specimens of this type show internal phloem in the region where the branches arise. Apparently these specimens show reversion in several particulars. The appearances receive ready interpretation by the theory here advocated; there are here two separate but upright pinnae and two fused basal pinnae.

Still other specimens show two fertile spikes, one arising in the normal position and another $8-10 \mathrm{~mm}$. above it (Fig. 27). In a specimen of this sort which was sectioned, the lower spike had a double vascular supply, and therefore represents two fused basal pinnae, while the higher (smaller) spike was supplied by a single strand which arose from near one edge of

${ }^{1}$ See Bull. Torrey Bot. Club, xxiv. 1897 , p. $5^{8}$. 
the U-shaped petiolar trace, and hence must be considered a single pinna. $^{1}$

Cases where one or more pinnae of the sterile segment bear sporangia have been earlier figured for several species, especially B. Lunaria (see Bower, 6, p. 443); Fig. 25 represents a case of this kind occurring in B. obliquum. The branch of the sterile segment which appears to be median in this figure is really a lateral branch which has been turned upward in preparing the herbarium specimen. An examination of the specimens of Botrychium in the Gray Herbarium shows that (I) almost all species occasionally show the feature illustrated in Fig. 25, and (2) in the smaller-leaved species the sterile leaflets frequently bear a few sporangia along the margin. The latter case resembles the half-sterile pinnae which may be seen on almost any plant of Osmunda regalis. These cases indicate that the whole leaf was at one time fertile, and that in the course of evolution a division of labour has occurred (cf.Osmunda Claytoniana), resulting in the sterilization of all of the pinnae except the basal pair, which have become specialized by turning upright (as is the case in Aneimia) and finally fusing. But in certain cases reversions occur, giving a clue to the probable evolutionary history of the genus.

Bower rejects the evidence afforded by these 'sports', considering the cases of double spikes merely instances of splitting or chorisis. I do not think that the cases here adduced can be disposed of in this simple way. If three or four spikes arose from the same point, the objection might be more significant, but in the plants of $B$. obliquum with three spikes two are paired and the third larger one arises from a lower point on the petiole. It seems clear that in this case there are two pairs of fertile pinnae, the basal pair of which are fused. Even in case two spikes are present they may arise from different points and may have a single or double vascular supply, as has been shown. The structural features are completely and easily explained on the view that a spike represents one or more pinnae of a leaf. Bower admits the cogency of the argument derived from the occasional fertility of pinnae which are usually sterile, but refers to the view of Goebel that sporangia are parts sui generis, and hence may occur on members of different rank. Apparently Bower does not endorse this view, and surely such an argument should be reserved as a last resort, for to admit it would rob comparative morphology of much of its meaning.

Among the species of Ophioglossum which have had their petiolar structure examined, $O$. lusitanicum has a comparatively simple structure. Prantl's account (18) shows that the leaf-trace early divides into three strands, one central and two lateral; these three arrange themselves as the angles of a triangle, and from each lateral strand there breaks off

\footnotetext{
1 See Note at end of paper.
} 
another strand; the last two move towards each other, fuse, and supply the fertile spike. The plan shown in $O$. vulgatum, as described by Holle (14) and verified in my own specimens, is closely related to that in O. lusitanicum, differing chiefly in that the petiolar strands are more numerous, that is, the three strands break up into about ten (there may be as many as fifteen) and are disposed in an ellipse, or rather a semicircle, for the strands on the adaxial side generally form nearly a straight line. The latter strands represent the right- and left-hand edges of the original petiolar strand, and they higher up anastomose to form three to five strands which pass up into the fertile spike, while the remaining strands branch extensively as they pass up into the sterile segment. The plan here exhibited differs from that seen in $B$. ternatum in that the vascular supply of the petiole early breaks up into a number of strands instead of remaining a single $\mathrm{U}$ - or $\mathrm{C}$-shaped strand. In both genera the vascular supply of the fertile spike is derived from the two free edges of the main petiolar system. This is well illustrated by the small species O. Bergianum, of which Bower $\left(6\right.$, p. $\left.46_{3}\right)$ says 'the single leaf-trace strand may long remain undivided, giving off two lateral strands which fuse on the adaxial side to form the supply for the spike: further up the strands of both sterile lamina and of fertile spike may branch again'. Campbell (9) has figured the disposition of the vascular bundles in the petioles of certain other species belonging to the section Euophioglossum. Assuming that the origin of the curved series of bundles in these petioles is the same as in those in which the origin has been traced, namely, from repeated division or branching of a curved leaf-trace, Campbell's figures show that several other species, including $O$. moluccanum and $O$. californicum, agree with $O$. lusitanicum in having the vascular supply of the fertile spike derived from the edges of the curved leaf-trace.

In the section Ophioderma the leaf-trace at its origin consists of from four to five strands arranged in a $U$, as is clearly shown by Bower's figures (5) of 0 . pendulum and 0 . simplex. In leaves which bear a fertile spike the edges of the $U$ soon close in to form a circle, and several strands which represent the two free edges of the trace constitute the supply of the fertile spike, exactly as in Euophioglossum. This may be seen from Campbell's figures of $O$. intermedium and $O$. pendulum, though it is only fair to say that this writer draws a different inference from his studies of these species.

The section Cheiroglossa, represented only by $O$. palmatum, is the most specialized in the genus. As in Ophioderma, the vascular supply of the leaf arises as several strands (5) which form a leaf-trace, becoming more and more curved until a circle of over a dozen strands is formed. From the adaxial side of this circle break off about four strands to supply the fertile spike. So far the behaviour is exactly as in Ophioderma, but, as Bower's figures show, from what now constitute the free edges of the 
leaf-trace there break off other sets of strands; those which break off from one edge supply the second spike, and those from the other edge supply the third spike. In other words, the vascular supply of the first spike is derived from both edges of the leaf-trace, while that of subsequent spikes may be derived from only one edge. According to the reasoning here employed, it may be inferred that the lowest spike in this specimen represents two fused lobes of the leaf, while the next two spikes represent single lobes. Whether any particular spike arises from one or from both edges of the leaf-trace can be determined only by the study of serial sections, and not by an inspection of the external surface, as has too often been done. Bower lays much stress on the observation that the spikes do not generally arise from the margin of the leaf, yet the only transverse sections which he figures $(6$, p. 463$)$ clearly show that in the case of the three spikes so represented the origin of the vascular supply at any rate is truly marginal, i. e. derived from the free edges of a curved leaf-trace made up of a number of separate strands. Probably most morphologists would place more reliance on the disposition of the vascular skeleton than on the superficial 'flesh' which clothes the skeleton.

The monotypic Asiatic genus Helminthostachys presents points of considerable difference from the other two genera. Farmer and Freeman (11) have given the best account of the mature sporophyte, while the young sporophyte is considered by Lang (16) in his paper on the gametophyte. By means of material kindly supplied by Dr. J. C. Willis, Director of the Royal Botanic Garden at Peradeniya, Ceylon, I have had the opportunity of verifying earlier accounts, while I have been able to study the structure of a young specimen kindly placed at my disposal by Professor Jeffrey of Harvard University. In the mature plant the single leaf-trace forks before it emerges from the cortex of the creeping rhizome, and soon repeats the process several times, forming a nearly circular row of eight to ten strands which soon become concentric. From one of the adaxial edges of this broken circle a strand breaks off, ${ }^{1}$ turns towards the middle region of the petiole, and orients itself in the inverse position. Thus a section through the petiole shows a ring of bundles with an odd one in the middle, frequently somewhat nearer the adaxial side. Campbell (9) figures a specimen with two strands in the position of the odd bundle, and says that these strands 'remain separate and are those which later extend into the spike'. Inasmuch as this condition is not represented in any of the figures of Goebel (13), Bertrand (2), or Tansley (24), nor shown in my material, it would be very interesting to know whether it is the result of splitting of the odd bundle, or whether each of the bundles arises from one edge of the curved leaf-trace. Campbell's account gives no

1 This fact, I believe, was first pointed out by Gwynne-Vaughan in his paper on Archangiopteris (Ann. Bot., xix, I905, p. 259). 
information on this point. The vascular supply of the fertile spike is derived partly from the odd bundle and partly from two strands which branch off from the right and left edges of the curved series of bundles which constitute the leaf-trace, but the odd bundle anastomoses with the main petiolar supply at the level of branching of the sterile segment, and emerges from this anastomosis as a pair of strands. Thus the vascular supply of the fertile spike consists of four strands. Upon this rather complicated system the young plant throws some light. Lang finds that the first leaves borne by the sporophyte contain only two bundles, derived by the splitting of a single leaf-trace. In this respect, therefore, the young plant resembles Botrychium. The small plant which came into my hands bore a fertile spike but possessed a simpler structure than the adult plant. The lower part of the petiole shows only four strands, two adaxial and two abaxial, i. e. the leaf-trace forks twice instead of three times as is the case in older plants. About half-way up the petiole, one of the adaxial strands gives off a rather small strand from the side which corresponds to one of the free edges of the curved leaf-trace (Fig. 22); the new strand takes a place midway between the two adaxial strands and runs up to the place where the fertile and sterile segments separate; here it anastomoses with the main strands (which in the meantime have united edge to edge) and finally emerges to supply the fertile spike. In this specimen therefore the vascular supply of the spike is derived from one edge of the curved leaf-trace, and it will be recalled that in the mature plant part of the supply is so derived. We have already seen that in B. obliquum a single pinna may be fertile or may even turn upward and constitute a fertile spike, and it has been argued that some of the spikes of Ophioglossum palmatum may represent single pinnae or lobes, so that it appears probable that in the highly specialized Helminthostachys a single pinna functions as a fertile spike.

The various theories regarding the fertile spike may now be considered in the light of the foregoing observations. The early suggestion of Roeper (20) that two fused leaves are present in the aerial part of Botrychium is easily disproved by the well-known fact that a single bundle arises from the central cylinder of the stem, leaving a well-marked gap, hence the whole structure constitutes a single leaf. The same fact disposes of Braun's surmise (7) that the fertile spike represents an axillary bud, for the vascular supply of the spike arises from the single leaf-trace, not from the central cylinder.

The position of those who hold with Goebel that the fertile spike is a ventral lobe of a leaf is, as Bower remarks, somewhat obscure. If the organ is really ventral in origin, the vascular system ought to exhibit this feature, but it has been shown that in Botrychium, and probably in the other genera of the family, the origin of the vascular supply of the fertile 
spike is marginal or slightly away from the margin on the abaxial side. No examples of true ventral lobes have been adduced; the sporocarp of Marsilia is stated by Van Tieghem (25, p. 1405$)$ to be such, but sections through the petiole at the point of attachment of the sporocarp (see Fig. 2I) show that the origin is similar to that of the leaflets, namely, from one edge of a curved leaf-trace. Goebel (13) has described a species, $M$. polycarpa, in which several sporocarps arise in acropetal succession on one side of the petiole. The fertile lobes of Aneimia and of Schizaea are likewise lateral in origin, as a study of their vascular structure shows. Apparently the 'ventral lobe' has a merely hypothetical existence outside of teratology.

To bridge over the gulf which exists between the bryophytes and pteridophytes, as Campbell proposes to do in deriving Ophioglossum from Anthoceros, were indeed a consummation devoutly to be wished, but the gulf seems still to exist, for even in Ophioglossum simplex the aerial organ is borne laterally on a stem, the central cylinder of which is perforated by a gap at the point of exit of the traces supplying this organ. Even if it could be proved that the fertile segment is the main structure in the aerial organ and the sterile segment only an appendage, the sporangiophore is still a lateral organ, which arises from the stem just as does a leaf. Campbell's latest contribution (9) on the subject seeks to show that the vascular supply of the fertile spike is not secondarily derived from the main bundles of the petiole, but that it can be traced to the base of the petiole. Hence the fertile spike is considered to be not a secondary but a terminal structure. According to this mode of reasoning, the basal pinnae in the leaf of Osmund $\alpha$ are terminal, for their 'divergents' (see 2) may be traced far down through the petiole. Similarly, in Botrychium virginiamum, the divergents which pass off to the fertile spike may be seen for some distance below the point where the strands of the spike break off from the main supply, but the same is true of the divergents belonging to the divisions of the sterile segment. In this species the strands which supply the fertile spike do not break off until within a short distance below the point where the spike is visible externally, but appear very distinctly to be 'secondarily given off from the main bundles of the petiole'. The evidence for Campbell's view would be more conclusive if his figures left less in doubt as to the actual course of the vascular bundles which form the basis of his argument. All the cases where serial sections have been studied support the view that the strands which supply the fertile spike arise from near the edges of the leaf-trace, as do those supplying the pinnae of a fern leaf.

The theory of Bower and others who consider the aerial part of the Ophioglossaceae to be a single sporophyll of a strobilus receives small support from the present investigation. The examination of the vascular supply of the fertile spike and the sterile pinnae of the leaf has shown the close similarity between Botrychium and an ordinary fern. The similarity 
between B. virginianum and Osmunda in this respect is so striking that, when considered in connexion with the other filicinean characters of Botrychium, we must conclude either that this genus has been derived from fern ancestors, or that ferns have been derived from Ophioglossaceae. The latter alternative is adopted by Campbell (8), but is not countenanced by Bower. Signs of high specialization are apparent in the family, which accordingly is not a favourable point of departure for other groups. Without attempting to discuss in detail the evidence adduced by Bower for linking Ophioglossaceae with the Lycopods, certain filicinean features of the former group may here be mentioned, in addition to the structure of the petiole :-

I. The Ophioglossaceae belong distinctly to the large-leaved group. Although it is not impossible that large leaves may have arisen more than once in evolution, it is hard to believe that so great similarity of structure should have been attained independently.

2. The endarch xylem (mesarch in Helminthostachys) is in sharp distinction to the exarch condition seen in most Lycopods. Since Tmesipteris has mesarch xylem this criterion is not so reliable as others.

3. The central cylinder of Ophioglossaceae is hollow and is perforated by leaf gaps. This fact places the family in the group Pteropsida. Bower's effort to show that a phyllosiphonic stele occurs also in Tmesipteris (6, p. 487 ) has been shown by Jeffrey (15) to be a misconception. Ophioglossum cannot be linked with Lycopodium by means of Tmesipteris or Phylloglossum, which are both outspoken members of Lycopsida.

4. Those who have studied the gametophytes of the three genera of Ophioglossaceae are agreed in considering their characters unmistakably filicinean, though specialized in connexion with the subterranean habit. The multiciliate sperm merits special mention.

In view of the evidence in favour of the filicinean affinities of the family it is appropriate to inquire which of the ferns are most closely related. When one considers the isolation of the family as a whole, and the differences between the genera, especially shown in the monotypic Helminthostachys, it becomes apparent that the family diverged from the main filicinean stock at a very remote date. The large sporangia opening simultaneously and lacking an annulus, the eusporangiate habit, the usually vertical rhizome, the gap in the leaf-trace formed at the point of exit of the strands which supply pinnae, indicate that the affinities of the family are with the group Simplices, especially with Osmundaceae and Marattiaceae. More than this cannot be safely inferred from the data at present available.

The evidence brought forward in the present study supports the earlier view that this family shows a series of reduced forms. Starting with a fern whose leaves bore sporangia over the whole of the lower surface, there has apparently been a sterilization of certain leaflets, similar to what may be seen in Osmunda Claytoniana, except that in the present case it is the basal 
ones which remained fertile. We may surmise that the next step was the raising of the fertile pinnae into the vertical position, so that the ancestral plant at this stage resembled Aneimia, as is shown in the instances of reversion in Botrychium obliquum. The next step was the fusion of the two fertile pinnae to form the fertile spike, and this produced the genus Botrychium, of which the large-leaved forms are, according to this view, the most primitive. Bower (6) has shown that there is a remarkable sequence of forms, which we may take the liberty of arranging backwards thus: Botrychium Lunaria, B. simplex (various forms), Ophioglossum vulgatum, O. Bergianum. Within the genus Ophioglossum there are signs of increasing complexity leading to O. palmatum; also, as Bower suggests (p. 479), a probable line of reduction including $O$. pendulum, intermedium, simplex. On the other hand both the rhizome and the leaf of Helminthostachys indicate that this genus represents an ascending line which early branched off from the composite form which is believed to have resembled Botrychium.

My hearty thanks are due to a number of friends who have kindly supplied material used in the present study: to Dr. J. C. Willis, Director of the Royal Botanic Garden at Peradeniya, Ceylon, for Helminthostachys ; to Professor E. C. Jeffrey, for a young specimen of Helminthostachys, and for the use of the photographic equipment of the Laboratory of Phanerogamic Botany at Harvard University; to Mr. J. C. Parlin, for several species of Botrychium; to Mr. F. W. Bachelder, for a generous supply of abnormal Botrychium obliquum; to Professor G. L. Goodale and Mr. R. Cameron for many ferns from the Harvard Botanic Garden; and to Professors A. F. Blakeslee and N. L. Britton, Mr. A. J. Eames, Professor J. W. Harshberger, Dr. O. W. Knight, Mr. C. H. Knowlton, and Mr. C. S. Ridgway for other material.

\section{SUMmaRY.}

I. The pair of vascular bundles which supply the fertile spike in Botrychium virginianum arise from near the two edges of a trough-shaped leaftrace which is generally split into halves. Each of these bundles leaves a gap in the leaf-trace, which is obscured by the slight divergence of the bundles from the trace. Similar gaps occur in Osmundaceae, Polypodiaceae, and other families of ferns.

2. The main vascular supply of the petiole runs into the sterile segment, where the bundles which supply the pairs of leaflets arise in exactly the same manner as those of the fertile spike. It is therefore inferred that the fertile spike represents two fused leaflets or pinnae, namely the basal pair, of a fern leaf.

3. In B. ternatum and B. obliquum the bundles which supply the fertile spike arise directly from the edges of the trough-shaped leaf-trace. The 
bundles of the branches of the fertile spike, however, leave either a distinct gap, or a more or less degenerate one. The condition found in these species is therefore considered to be derived by reduction from that found in B. virginianum.

4. Certain other species of Botrychium show no trace of this gap, and are considered to be further reduced.

5. Abnormal specimens of B. obliquum show either a pair of fertile spikes, in which case they resemble Aneimia, or a pair of spikes with an additional larger one inserted somewhat below the pair and corresponding to two fused spikes. The internal structure of these and other similar specimens bears out the view here adopted (see 2 above), hence such cases are to be regarded as reversions.

6. In Ophioglossum the bundles leading to the fertile spike break off from the two edges of the curved row of strands which represents the leaf-trace. This condition is considered to be derived from that found in Botrychium.

7. The vascular supply of the fertile spike in Helminthostachys is derived principally from one edge of the curved row of bundles which forms the leaf-trace; this is more clearly seen in a young specimen. It is inferred that the fertile spike in this genus represents a single pinna.

8. The Ophioglossaceae are considered to be related to the ferns and to have sprung from near the level of Osmundaceae. They appear to have branched off from the primitive stock at a very remote period.

9. A study of the internal structure of the leaf in Ophioglossaceae strongly supports the view of Roeper that the fertile spike represents two fused basal pinnae, though in certain cases a spike represents a single pinna, which, however, does not arise ventrally. No support is afforded to the view of a strobilar origin or of a direct derivation from Hepaticae.

$$
\begin{gathered}
\text { Orono, Maine, } \\
\text { August, I909. }
\end{gathered}
$$

NotE.-During September, I909, the writer visited at Sandwich, N.H., one of the stations where abnormal Botrychium obliquum had been found. A number of additional specimens were collected, and it was observed that nearly all of the unusual forms mentioned on pp. 7-9 are exemplified also in the variety dissectum. One specimen approaching dissectum had the fertile spike sterile with the exception of part of one of the basal branches. At this station and at Manchester, N.H., the number of abnormal specimens amounts to at least io per cent.

\section{Literature Cited.}

1. Bachelder, F. W.: Preliminary list of plants growing without cultivation in the vicinity of Manchester, N.H. Proc. Manchester Inst., iv, part 2, I909.

2. Bertrand, C. Eg., and Cornaille, F.: Étude sur quelques caractéristiques de la structure des Filicinées actuelles, I. Trav. et Mém. de l’Univ. de Lille, X; xxix, I902, pp. I-22I.

3. Bower, F. O.: Studies in the morphology of spore-producing members. Preliminary statement on the Lycopodinae and Ophioglossaceae. Proc. Royal Soc., London, 1, 1891, pp. $265-73$. 
4. Bower, F. O.: Studies in the morphology of spore-producing members. II : Ophioglossaceae. London, 1896.

5. - Ophioglossum simplex, Ridley. Ann. Bot., xviii, I904, pp. 205-16, P1. XV.

6. - The origin of a land flora. London, I908.

7. Braun, A. : Flora, I 839 , p. 30 I.

8. Campbell, D. H. : On the affinities of the Filicineae. Bot, Gaz., xv, I89o, pp. I-7.

9.

10. Celakovsky, L. : Untersuchungen über die Homologien der generativen Producte der Fruchtblätter bei den Phanerogamen und Gefässkryptogamen. Jahrb. wiss. Bot., xiv, 1884, pp. 29I-378, Pls. XIX-XXI.

11. Farmer, J. B., and Freeman, W. G.: On the structure and affinities of Helminthostachys zeylanica. Ann. Bot., xiii, I 899, pp. 42 I-45, Pls. XXI-XXIII.

12. Goebel, K. : In Schenk's Handbuch, III. Berlin, I 884 .

13. : Organographie der Pflanzen. Jena, Igor.

14. Holle, H. G. : Ueber Bau und Entwickelung der Vegetationsorgane der Ophioglosseen. Bot. Zeit., xxxiii, I875, p. 24I.

15. Jeffrey, E. C.: Are there foliar gaps in the Lycopsida? Bot. Gaz., xlvi, I908, pp. $24^{\mathrm{I}-5^{8}}$. Pls. XVII, XVIII.

16. LANG, W. H.: On the prothalli of Ophioglossum pendulum and Helminthostachys zeylanica. Ann. Bot., xvi, I902, pp. 23-56, Pls. I-III.

17. Mettenius, G. H. : Farne des Bot. Gart. zu Leipzig. $\quad \mathbf{1} 856$.

18. Prantl, K.: Helminthostachys zeylanica und ihre Beziehungen zu Ophioglossum und Botrychium. Ber. d. deutsch. bot. Ges., i, I883, pp. 155-6r.

19. PresL, K. B. : Supplementum tentaminis pteridographiae. 1845 .

20. Roeper, J.: Observationes aliquot in florum inflorescentiarumque naturam. Linnaea, i, 1826, pp. $433-570$.

21. : Zur Flora Mecklenburgs, i, I843, p. Io8.

22. - Z Zur Systematik und Naturgeschichte der Ophioglosseae. Bot. Zeit., xvii, I 859 , p. $24 \mathrm{I}$.

23. Sinnott, E. W.: Foliar gaps in the Osmundaceae. Ann. Bot. xxiv, igro.

24. Tansley, A. G.: Lectures on the evolution of the Filicinean vascular system. New Phyt., vi, vii, 1907-I908.

25. Van Tieghem, Ph.: Traité de Botanique. $2^{\ominus}$ éd., Paris, i 89 I.

\section{EXPLANATION OF PLATES I AND II.}

Illustrating Dr. Chrysler's paper on the Ophioglossaceae.

\section{PLATE I.}

Fig. I7. Todea barbara. Transverse section through midrib of leaf at level of origin of a pair of pinnae. The vascular supply of one pinna is visible on the right side. The adaxial side is placed upward in this and all the other figures. $\times$ Io.

Fig. 18. Osmunda Claytoniana. Transverse section through midrib of leaf at level of origin of a pair of pinnae. The gaps left by the exit of the branches supplying the pinnae have closed. $\times 20$.

Fig. 19. Botrychium virginianum. Transverse section through petiole, showing the origin of the strands which supply the fertile spike. These strands appear at the upper side of the figure. $\times 20$.

Fig. 20. Botrychium ternatum. Transverse section through axis of the fertile spike, showing the mode of origin of two branch strands. $\times 25$. 


\section{8 Chrysler.-Nature of the Fertile Spike in the Ophioglossaceae.}

Fig. 21. Marsilia quadrifolia. Transverse section through petiole, showing the mode of origin of the strand which supplies the sporocarp. This strand appears at the left, and is enclosed in dense sclerenchyma. $\times 9$ o.

Fig. 22. Helminthostachys zeylanica. Transverse section through petiole of a young specimen. The odd strand in the upper part of the figure arises from the strand at its right and supplies the fertile spike, the base of which is visible as a ridge on the surface of the petiole. $\times 3^{\circ}$.

\section{PLATE II.}

Fig. 23. Aneimia tomentosa, Swartz, var. fulva Hook and Bak. Introduced for comparison.

Fig. 24. Botrychium obliquum, Muhl. Specimen with a pair of fertile spikes.

Fig. 25. Same. Specimen with one fertile pinna in the sterile segment. This pinna is really lateral, but has been bent upward in pressing the plant.

Fig. 26. Same. Specimen with a pair of fertile spikes in addition to the ordinary one, which is seen to be inserted further down than the pair.

Fig. 27. Same. Specimen with an extra fertile spike, which in this case represents a single pinna.

Fig. 28. Same. Specimen with two fertile spikes partly fused. 

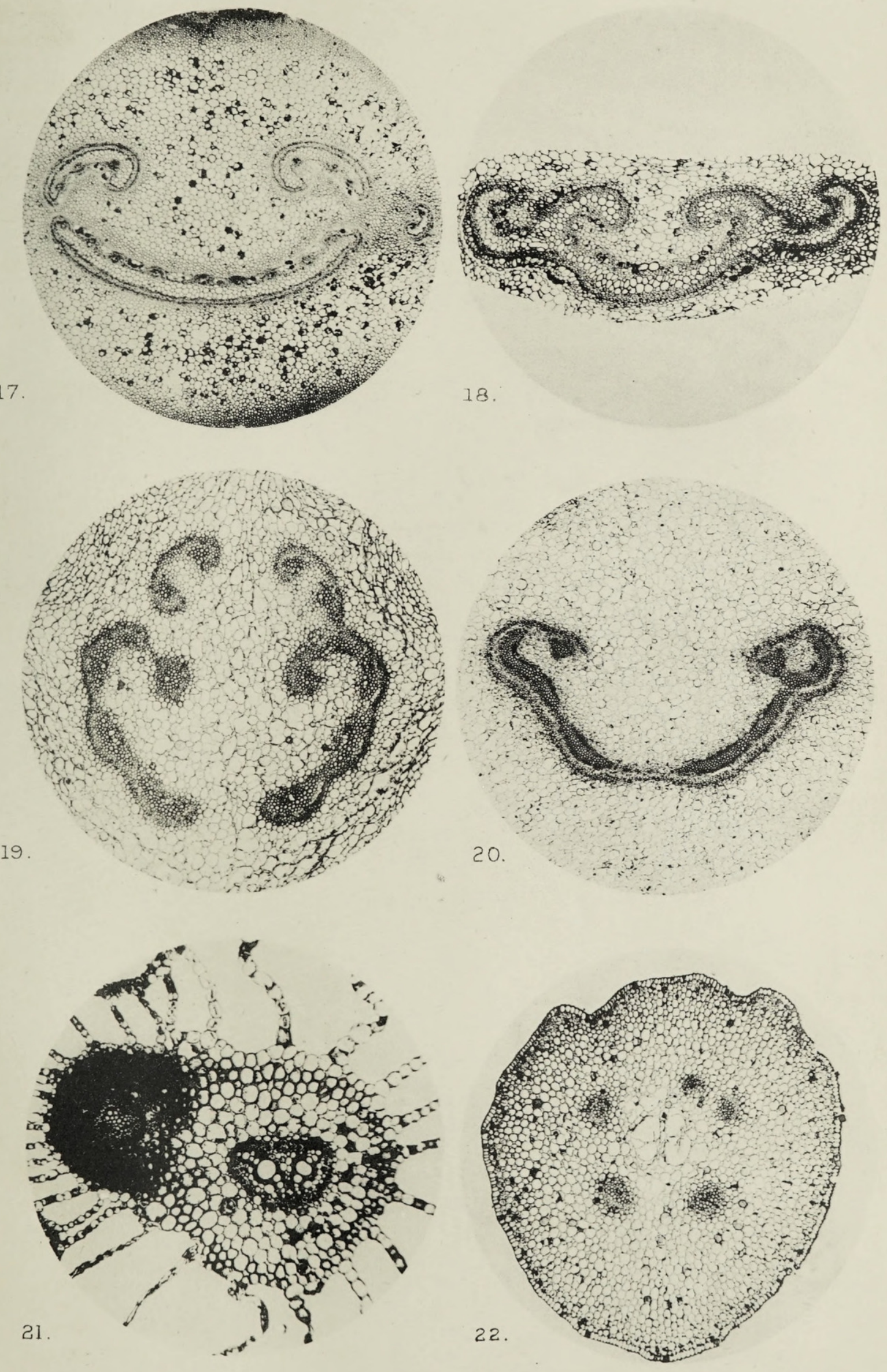
हैं
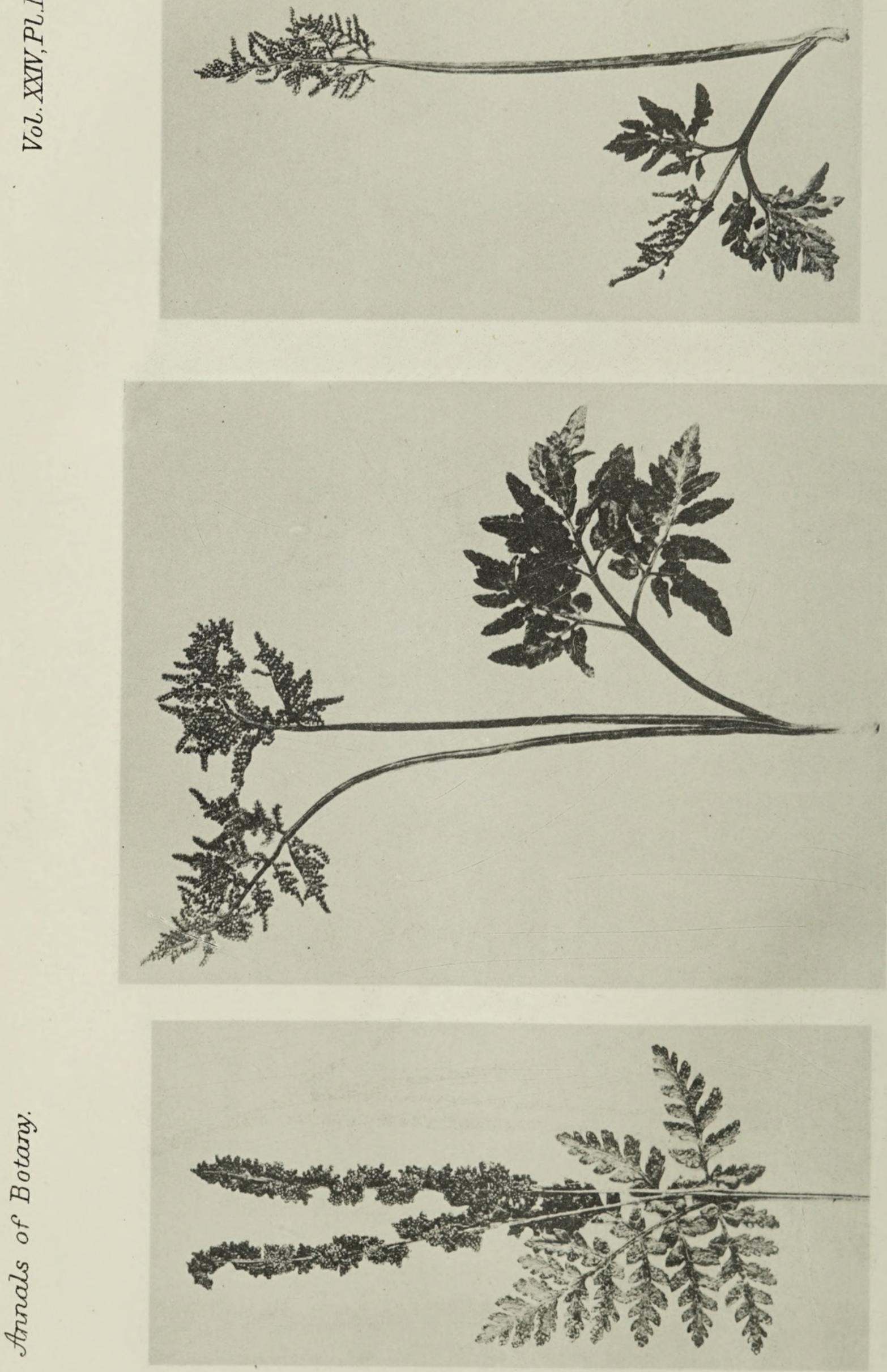

ن 


\section{$2 \mathrm{BHL}$ Biodiversity Heritage Library}

Chrysler, Mintin Asbury. 1910. "The nature of the fertile spike in the Ophioglossaceae." Annals of botany 24, 1-18.

https://doi.org/10.1093/oxfordjournals.aob.a089249.

View This Item Online: https://www.biodiversitylibrary.org/item/262605

DOI: https://doi.org/10.1093/oxfordjournals.aob.a089249

Permalink: https://www.biodiversitylibrary.org/partpdf/319757

\section{Holding Institution}

New York Botanical Garden, LuEsther T. Mertz Library

\section{Sponsored by}

BHL-SIL-FEDLINK

\section{Copyright \& Reuse}

Copyright Status: Public domain. The BHL considers that this work is no longer under copyright protection.

This document was created from content at the Biodiversity Heritage Library, the world's largest open access digital library for biodiversity literature and archives. Visit BHL at https://www.biodiversitylibrary.org. 